\title{
The epidemiology of varicella-zoster virus infections:
} a mathematical model

\author{
G. P. GARNETT ${ }^{1 *}$ AND B. T. GRENFELL ${ }^{2}$ \\ ${ }^{1}$ Department of Animal and Plant Sciences, Sheffield University \\ ${ }^{2}$ Department of Zoology, Cambridge University, Cambridge CB2 3EJ
}

(Accepted 24 January 1992)

\begin{abstract}
SUMMARY
Herpes-zoster is caused by the reactivation of varicella-zoster virus (VZV). In this paper different hypotheses of how this re-emergence of virus comes about are reviewed and discussed. From these hypotheses, and epidemiological data describing the initial transmission of the virus, a mathematical model of primary disease (varicella) and reactivated disease (zoster) in developed countries is derived. The steady-state age distributions of zoster cases predicted by this model are compared with the observed distribution, derived from a review and analysis of published epidemiological data. The model allows differentiation between published hypotheses in which age of host may or may not influence the probability of viral reactivation. The results indicate that the probability of reactivation must increase with age to allow the observed pattern of zoster cases. The basic mathematical model presented provides a conceptual framework, which may be extended to assess possible control programmes.
\end{abstract}

\section{INTRODUCTION}

Varicella (chickenpox) and herpes-zoster (shingles) have a common aetiological agent varicella-zoster virus (VZV), zoster being the re-emergence (reactivation) of latent virus $[1,2]$. There is an extensive literature describing the dynamics of varicella incidence in terms of simple mathematical models $[3,4]$, and HopeSimpson has formulated a qualitative model of the varicella-zoster system [5-7]. However, no attempt has yet been made to produce a quantitative model of infection with $V Z V$ infection which explicitly includes the dynamics of zoster. Such a model is proposed here. Its development should help in understanding the mechanisms which lead to zoster, the disease's influence on the population dynamics and persistence of varicella-zoster virus, and most importantly the relationship between the incidence of the two diseases.

The 1970s saw the development by Takahashi of a live attenuated vaccine for varicella [8]. An application for a licence to use the vaccine has been submitted to the US Food and Drugs Administration [9]. A decision about the vaccines licence is expected during 1991 (L. Fehrs, personal comm.) and it has been suggested that

* Present address : Parasite Epidemiology Research Group, Department of Biology, Imperial College, London SW7 2BB. 
the vaccine should be given to all healthy children [10-12]. Such a large scale vaccination programme would involve dramatic changes in the epidemiology of the virus, which may alter the severity of remaining cases. The clear need to assess the epidemiological implications of such a vaccination programme makes the construction of a model of the population biology of the virus a particular priority. This is the first of a series of papers which looks at the population biology of transmission of VZV and reactivation. The epidemiological implications of mass vaccination will be explored in detail in subsequent papers. The present paper proposes a simple mathematical model, which describes the relationship between the incidence of varicella and zoster. The model's predictions are tested by comparison with empirical observations. The paper is divided into four sections. Firstly, a review of the literature is used to formulate a basic model. Secondly, estimates of the model parameters are derived and epidemiological data on the incidence of the two diseases are reviewed. The third and fourth sections respectively compare the equilibrium model predictions with observed epidemiological patterns, and discuss the implication of these results.

\section{EPIDEMIOLOGICAL BACKGROUND AND MODEL STRUCTURE}

The biology of infection

Varicella results from primary infection with varicella-zoster virus. The pathology of the disease is described by Plotkin [13] and Straus [14]. Varicella can be categorized epidemiologically as a directly transmitted viral infection of childhood. Initially individuals pass through susceptible, incubation, and infectious periods, thereby achieving effectively lifelong immunity to subsequent primary infection. Like other members of the Herpesviridae the virus persists in a latent phase and on reactivation re-emerges and produces disease, in this case herpes-zoster (shingles) [15]. The reactivated virus migrates down nerve cells causing neural damage, the segmental pattern of which [16] gave rise to the belief that the virus is latent within dorsal root ganglia [7]. In fact, the virus has never been isolated during postmortems of people without clinical zoster [1]. However, viral RNA and DNA has been detected within dorsal root ganglia $[17,18]$.

\section{The model}

\section{Initial infection}

Because we are interested in the reactivation in later life of an earlier infection, even the simplest model of VZV must explicitly consider host age structure. The following formulation therefore describes the pattern of viral transmission in a large age-structured community of constant size $N$. It is compartmental in structure consisting of a set of partial differential equations [19,20], which describes the densities of individuals classified into subgroups. The host population is divided into the following categories : passively immune infants with maternally derived antibodies $(M)$, susceptible individuals $(S)$, incubators who are infected but not yet infectious $(E)$, and infectious individuals $(I)$. The formal structure of the model, which is expressed schematically in Fig. 1, is presented in the Appendix. The parameters $\delta, \sigma$ and $\nu$ are, respectively, the rates of transition of people out of the categories for maternal immunity, viral incubation, and 


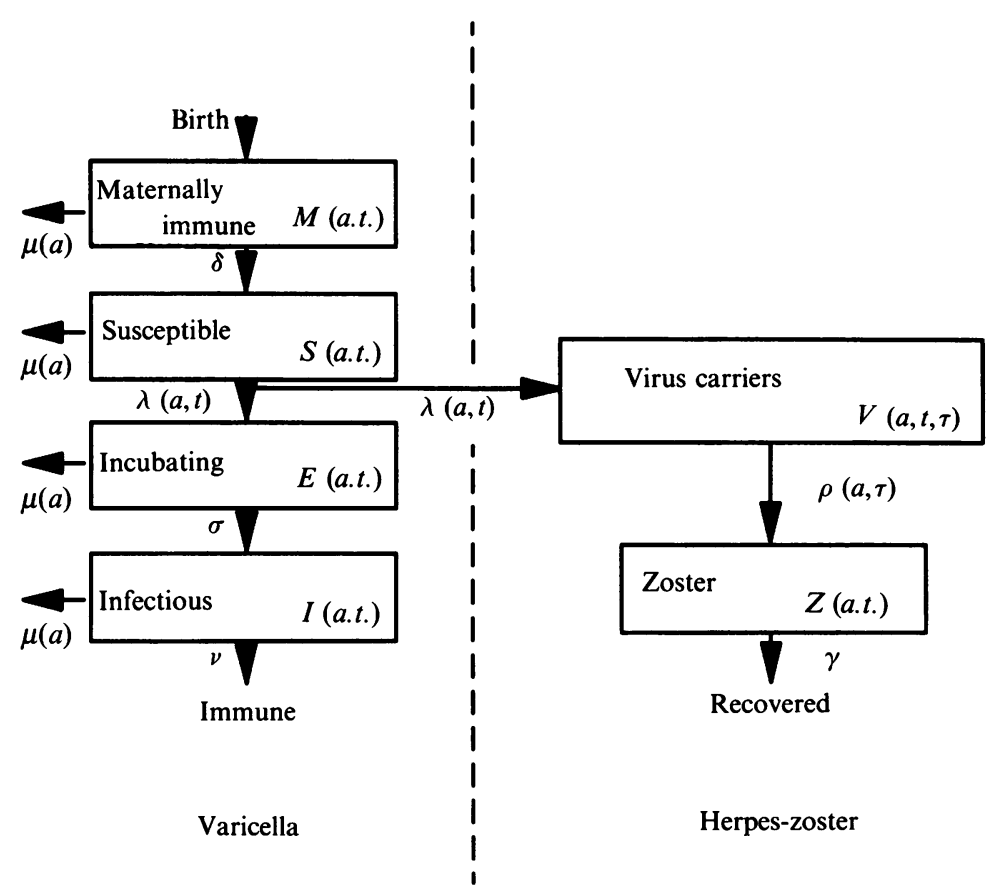

Fig. 1. A diagrammatic representation of an age-structured compartmental model describing the prevalence of varicella and herpes-zoster.

infectiousness. The variable $\lambda(a, t)$, the age specific 'force of infection' [20] is the instantaneous rate at which susceptible individuals of a given age acquire infection, which depends upon the age specific transmissibility of and susceptibility to the virus and the mixing between age groups (see Appendix). Immunity acquired through primary infection is assumed to produce lifelong protection against varicella. Individual hosts are also assumed to die at a per capita age specific death rate $\mu(a)$. The relationship between the death rate and age is discussed below. The model described so far is a standard formulation employed in the representation of directly transmitted primary micro-parasitic infections like varicella, which engender permanent subsequent immunity, and has been described and analysed in detail $[19,20]$.

\section{Herpes-zoster}

In order to represent the incidence of zoster we need two new state variables in parallel to the categories describing the incidence of initial infection. These two categories are 'virus carriers', $V(a, t, \tau)$, where $\tau$ is the time since initial infection, and 'zoster cases', $Z(a, t)$. The transitions in this model are shown in Fig. 1 and the dynamics of $V$ and $Z$ are described by the equations

$$
\begin{aligned}
& \frac{\partial V(a, t, \tau)}{\partial a}+\frac{\partial V(a, t, \tau)}{\partial t}+\frac{\partial V(a, t, \tau)}{\partial \tau}=-(\mu(a)+\rho(a, \tau)) V(a, t, \tau), \\
& \frac{\partial Z(a, t)}{\partial a}+\frac{\partial Z(a, t)}{\partial t}=\int_{0}^{a} V(a, t, \tau) \rho(a, \tau) d \tau-(\mu(a)+\gamma) Z(a, t) .
\end{aligned}
$$

A biological justification of these equations is as follows. 
(i) Origin of virus carriers. $V(a, t, 0)$ (the boundary condition of $V$ ) is the number of people of age $a$ who pass through infection and acquire virus at time $t$. This could either be expressed as the number of newly infected individuals $(\lambda(a, t)$ $S(a, t))$ or the number of people recovering from varicella $(\nu I(a, t))$. In practice, these alternatives produce very similar results - the former is adopted, as it appears the more realistic, given that vaccination can lead to the virus becoming latent [21].

(ii) Dynamics of virus carriers (Eqn. 1). The dynamics of $V$ then proceeds as a function of age $(a)$, time $(t)$ and delay $(\tau)$, which is the time since the cohort $V(a, t, \tau)$ was infected (when $\tau=0$ ). Carriers are either allowed to die (at rate $\mu(a)$ ) or to undergo reactivation into the zoster category (at rate $\rho(a, \tau)$ ).

(iii) Dynamics of zoster (Eqn. 2). The transition rate from virus carriers to zoster at age $a$ and time $t$ is controlled by the positive term in equation (2). Since carriers can undergo reactivation at any time since their infection, this rate is expressed as an integral of the reactivation rate $\rho(a, \tau) V(a, t, \tau)$ from $\rho(a, 0) V(a, t, 0)$ (i.e. individuals who reactivate immediately after primary infection) to $\rho(a, a) V(a, t, a)$ (i.e. individuals of age $a$ who were infected at birth). The reactivation function $\rho(a, t)$ controls the extent of reactivation over this range (see below). Finally zoster cases are lost by death (rate $\mu(a)$ ) and recovery (rate $\gamma$ ). The implicit assumption of this model, that individuals only acquire zoster once, is based on the observed infrequency of subsequent cases of zoster $[5,16]$.

\section{The reactivation function}

The reactivation function $\rho(a, \tau)$, is central to the relationship between the incidence of varicella and zoster. It represents the probability that virus will reactivate in the cohort of individuals aged $a$ who acquired initial infection $\tau$ time units previously. It is therefore possible to formulate hypothesis about mechanisms of viral reactivation in terms of the relationship between reactivation $(\rho)$, age $(a)$ and delay $(\tau)$ and the transmission intensity of varicella $\lambda(a, t)$. A description of the possible roles of transmission intensity of varicella is discussed in the accompanying paper [22]. A summary of the current hypotheses about the probability of reactivation is described in the following sections.

(1) External precipitants influence reactivation. Some studies suggest that an extrinsic provoking factor leads to reactivation, as is the case with herpes simplex type $1[23-26]$. The provoking factor is thought to act either by damaging the cutaneous areas of nerve cells, allowing the virus to enter these areas or by the process of damage which stimulates the virus within the nucleus to emerge [25]. Evidence for this hypothesis is based on a search, following diagnosis, for events which stimulated disease [24], a methodology fraught with difficulties. The simplest reactivation function which describes this hypothesis is

$$
\rho(a, \tau)=\alpha,
$$

where $\alpha$ is the constant proportion of virus carriers who would suffer herpes-zoster. In this case the reactivation function is independent of age and the time following initial infection. External precipitants of herpes-zoster, such as exposure to sunlight and draughts, should act in such a way and are consequently subsumed 
in the value of $\alpha$. This simplest hypothesis evokes tissue damage as the main influence on reactivation of the virus. In contrast the other hypotheses place emphasis on the influence of the host's immune response and are therefore agedependent.

(2a) Age-related reactivation. In a seminal paper Hope-Simpson [7] hypothesized that a fall in humoral immunity allows the virus, which he thought to be repeatedly stimulated into replication, to multiply and the migrate down the path of the nerves. In this framework, exogenous precipitants could also have such an effect if they influence the immune system, but not simply by causing direct damage to the cutaneous cells. Current research has changed the emphasis, from humoral to cell-mediated immunity (CMI) as the important factor which maintains protection from reactivation of VZV [28-30]. This is sensible, because cell-mediated products could inhibit the multiplication of the virus genome within the immunologically privileged site of viral latency, the nerve cells [31].

This gradual decline in specific immunity which allows the virus to reactivate when the degree of protection falls below a threshold level, is most simply represented as a linear increase in reactivation with age.

$$
\rho(a, \tau)=\alpha+\phi_{1} a .
$$

Here, $\alpha$ is a background probability of zoster caused by other effects, as described above. If chance events, such as another illness which involves general damage to the immune system, play no part in the reactivation, then $\alpha$ would equal zero. The value of the constant $\phi_{1}$ depends upon how rapidly specific immunity fades.

Most cases of varicella occur in a relatively narrow age range (see later section on the estimation of the forces of infection). This means that equation (4) generates similar epidemiological predictions if delay since infection $(\tau)$ is substituted for age. Therefore age is used in these models, since it generates a simpler, more tractable, model structure.

$2 b$. The effect of increasing age on the immune system. Hope-Simpson also suggested that the declining competence of the immune memory in older individuals could lead to a more rapid reduction in the VZV-specific immunity [5]. In this case increasing age has an effect over and above the associated increase of time since initial infection. This possibility can be described by the general expression :

$$
\rho(a, \tau)=\alpha+\xi(a) .
$$

In contrast to equation (4), $\xi(a)$ increases faster than linearly with time. In practice, two alternative formulations for this equation were adopted:

(i) an exponential increase;

$$
\xi(a)=\mathbb{C}_{1}\left(e^{\left(\phi_{2} a\right)}-1\right), \quad\left(\mathbb{C}_{1} \text { is a simple scaling constant }\right)
$$

or (ii) a linear increase after a threshold age $(\iota)$

$$
\begin{array}{ll}
a \leqslant \imath & \xi(a)=0 \\
a>\imath & \xi(a)=\phi_{3}(a-\imath)
\end{array}
$$

Here immune competence starts to decline above age $\iota$ as the specific immunity begins to wane. These two functions are simple examples of how age may affect the 
system. In the former the rate of decline of specific immunity increases as age increases, and in the latter the decline in specific immunity starts at an age threshold.

Hope-Simpson also proposed that contact with circulating virus may influence the decline in VZV-specific immunity and thus inhibit zoster [5]. This possibility is dealt with in detail in the accompanying paper [22].

\section{The re-occurrence of zoster}

The above model implicitly assumes that individuals can only suffer a single episode of herpes-zoster. However, on recovering from herpes-zoster people still carry the virus and can consequently suffer further episodes of zoster as they still harbour latent virus $[7,16,32,35]$. Within Hope-Simpson's hypothesis this corresponds to a repeated fall in immunity after its reconstitution during an episode of herpes-zoster [5]. Estimates of the percentage of cases that are secondary vary from less than $1 \%$ [16] to $6 \%$ [5]. Because of this very low level we retain the assumption that individuals suffer zoster only once, which greatly simplifies the model.

\section{Natural mortality rates and the incidence of zoster}

In the case of the directly transmitted viral infections, measles, mumps and rubella, the majority of cases occur amongst school-children [36]. Because at a population level very few infections occur in the elderly there is often no need in mathematical models of these diseases to be concerned with the representation of processes amongst later age groups [19]. In such models all individuals can be assumed to survive until the mean life expectancy, after which they are removed from the compartments of the model. Using an age structured model it is possible to allow for an age-dependent death rate. This can be used to reflect the way the number of deaths increases gradually with age in a developed country. Such a function is particularly useful in any model of varicella-zoster infections, because zoster occurs in a wide range of ages, with a predominance of cases in older people. In the models presented here, the Gompertz survival function suggested by Anderson and May [19] is used. This corresponds to an exponential increase in the death rate:

$$
\mu(a)=\bar{\alpha} \exp (\bar{v} a) \quad\left(\bar{\alpha}=0.28 \times 10^{-3} ; \bar{v}=0.064\right) .
$$

The coefficients used in the equation are those estimated by Anderson and May [37] from the 1977 age structure of the population of England and Wales.

\section{Analysis of the model}

In this paper we present an analysis of the equilibrium (steady-state) behaviour of the model with respect to time; an exploration of the dynamic interaction of varicella and zoster incidence will be presented in a future paper. The equilibrium of the model can be characterized by a set of ordinary differential equations which describe the incidence of primary varicella infection, and a parallel set of partial differential equations (in terms of age and delay since infection) which reflect the incidence of zoster (see Appendix). Because at equilibrium the time dependency is eliminated these can be solved by following a birth cohort over increasing age in very small finite steps. This allows the examination of the age distribution of 
zoster cases at the model's steady state for the range of reactivation functions described above. In order to carry this out we require both empirical estimates of the model's parameters (and in particular the force of infection for varicella), and a description of the observed distribution of zoster cases by age for comparison with model results. These estimates are documented in the next section.

\section{EPIDEMIOLOGICAL DATA AND PARAMETER ESTIMATES}

Transition rates during infection. The model requires estimates of the rate of loss of maternally derived immunity in infants $(\delta)$ and the rate of loss of individuals from incubating, infectious and zoster categories $(\sigma, v$ and $\gamma$ respectively). These can be calculated as the reciprocals of the average duration of stay in the maternally immune, incubating, infectious and zoster categories [38]. The best estimates for these durations are presented in Table 1, along with the published sources from which they were derived.

Estimation of the forces of infection. Published data which records the incidence of varicella includes both age-stratified case reports and serological surveys. From these data it is possible to calculate the force of infection of viral transmission (sensu Grenfell and Anderson [45]; see Appendix) as a function of susceptible age. The method described by Grenfell and Anderson [45] was used. Here the parameters of a polynomial function characterizing the force of infection pattern are estimated by maximum likelihood, and from this the forces of infection (the instantaneous per capita rate at which individuals acquire infection) over age blocks are calculated. Serological surveys normally include fewer biases than case reports, although in the case of varicella large discrepancies exist between different serological surveys (Table 2). This is possibly a consequence of the relatively small sample sizes used in these surveys or because they are taken from different populations. Because early work done with the complement fixation test has proved unreliable $[15,50]$, only serological data from neutralization (NT), enzyme-linked immunosorbent assay (ELISA), and direct and indirect fluorescent antibody to membrane antigen (FAMA and IFAMA) tests were analysed. For comparison age-stratified case reports for varicella from developed countries $[33,40,51-53]$ were also analysed, and on the whole the results were consistent with those calculated from serological survey data (Table 2). Varicella has a peak in the forces of infection in the 5-10-year-old age class, and the mean age of infection for all serological survey and case report studies is 6.95 years. Because there is no definitive serological survey the mean forces of infection derived from all the serological surveys are used in the model (Table 2).

The occurrence of zoster. Epidemiological data which describe the incidence of disease by age are not as readily available for zoster as they are for varicella. Because VZV causes both varicella and zoster [15] tests for antibodies to VZV tell us virtually nothing about the prevalence of zoster. To learn about the pattern of zoster incidence we must therefore rely upon age-stratified case reports, however small and subject to bias these may be. A summary of published age-stratified case reports of zoster from developed countries is presented in Table 3. The reports portray the pattern of the emergence of zoster with different degrees of accuracy which depends upon the sample size, whether the data are taken from visits to 
Table 1. Estimates of epidemiological parameters taken from published data

\begin{tabular}{|c|c|c|c|c|c|}
\hline Parameter & $\begin{array}{c}\text { Estimate } \\
\text { used }\end{array}$ & $\begin{array}{l}\text { Sample } \\
\text { size }\end{array}$ & $\begin{array}{l}\text { Derived } \\
\text { value }\end{array}$ & $\begin{array}{c}\text { Measure of } \\
\text { variation : } 95 \% \\
\text { confidence } \\
\text { interval }\end{array}$ & $\begin{array}{l}\text { Sources } \\
\text { of data }\end{array}$ \\
\hline $\begin{array}{l}\text { Duration of } \\
\text { maternal } \\
\text { immunity }\left(\delta^{-1}\right)^{*}\end{array}$ & 5 months & $\begin{array}{r}38 \\
143\end{array}$ & $\begin{array}{l}4 \cdot 35 \text { months } \\
5 \cdot 34 \text { months }\end{array}$ & $\begin{array}{c}3 \cdot 55-5 \cdot 60 \\
4 \cdot 47-5 / 34\end{array}$ & $\begin{array}{l}{[39]} \\
{[41]}\end{array}$ \\
\hline $\begin{array}{l}\text { Incubation } \\
\text { period }\left(\sigma^{-1}\right)\end{array}$ & 14 days & 67 & $15 \cdot 13$ & $11-20$ & {$[42]$} \\
\hline \multirow{3}{*}{$\begin{array}{l}\text { Infectious } \\
\text { period }\left(v^{-1}\right)\end{array}$} & & $\begin{array}{l}184 \\
182\end{array}$ & $\begin{array}{l}13 \cdot 68 \\
14 \cdot 3\end{array}$ & $\begin{array}{l}\text { s.e. } 1 \cdot 12 \\
10-23\end{array}$ & $\begin{array}{l}{[3]} \\
{[43]}\end{array}$ \\
\hline & 5 days & $\mathrm{NS} \dagger$ & 5 days & NS & {$[42]$} \\
\hline & & NS & $\begin{array}{c}5 \text { days } \\
\text { mean } \ddagger \text { (weeks) }\end{array}$ & $\begin{array}{c}\text { NS } \\
\text { range } \\
\text { (weeks) }\end{array}$ & [13] \\
\hline $\begin{array}{c}\text { Duration of } \\
\text { zoster }\left(\gamma^{1}\right)\end{array}$ & 4 weeks & 72 & $4 \cdot 03$ & $0-12$ & [44] \\
\hline
\end{tabular}

* The values for $\delta$ were derived by fitting the curve $\exp (-\delta a)$ to the function $P(a)$, the proportion of infants immune at age $a$ months. For a shorter estimate see Ozaki and colleagues [40], where a sensible exponential decay could not be fitted to the observed data. $\dagger \mathrm{NS}$, not stated. $\ddagger$ Duration of the rash.

Table 2. The mean forces of infection for age groups, and the mean age of infection calculated from reliable serological surveys for varicella antibodies

\begin{tabular}{|c|c|c|c|c|c|c|c|c|}
\hline \multirow{2}{*}{$\begin{array}{l}\text { Location } \\
\text { (ref) }\end{array}$} & \multirow{2}{*}{$\begin{array}{l}\text { No. of } \\
\text { age } \\
\text { groups }\end{array}$} & \multirow{2}{*}{$\begin{array}{l}\text { Sample } \\
\text { size }\end{array}$} & \multirow{2}{*}{$\begin{array}{l}\text { Test } \\
\text { used }\end{array}$} & \multicolumn{4}{|c|}{$\lambda \mathrm{s}$ for the age group } & \multirow{2}{*}{$\begin{array}{c}\text { Mean age } \\
\text { of infection } \\
(\mathrm{yrs})\end{array}$} \\
\hline & & & & $1-4$ & 5-14 & $15-44$ & $44+$ & \\
\hline $\begin{array}{l}\text { West } \\
\text { Germany [46] }\end{array}$ & 16 & 330 & FAMA & $0 \cdot 12$ & $0 \cdot 10$ & 0.07 & $0 \cdot 01$ & $10 \cdot 6$ \\
\hline Seattle $[47]$ & 15 & 311 & ELISA & $0 \cdot 13$ & $0 \cdot 64 *$ & - & - & $6 \cdot 4$ \\
\hline Japan [48] & 9 & 170 & NT & $0 \cdot 18$ & $0 \cdot 20$ & $0 \cdot 45^{*}$ & - & $6 \cdot 8$ \\
\hline Israel [49] & 9 & 872 & IFAMA & $0 \cdot 10$ & $0 \cdot 14$ & $-0 \cdot 02^{*}$ & $-0.002 *$ & $13 \cdot 7$ \\
\hline Spain [50] & 7 & 510 & ELISA & $0 \cdot 23$ & $0 \cdot 31$ & - & - & $4 \cdot 3$ \\
\hline $\begin{array}{l}\text { Means for use } \\
\text { in the model: }\end{array}$ & & & & $0 \cdot 15$ & $0 \cdot 23$ & 0.07 & 0.01 & \\
\hline
\end{tabular}

* Values excluded from calculation of the means. The data are horizontal cross-sections rather than longitudinal which allow irregularities in the age profile caused by statistical variability.

doctors or hospitals, and upon how fine the age stratification is. Nevertheless a general picture does emerge (Fig. 2). This is best seen when all the data are merged using means weighted according to sample size (Fig. 2). The pattern is qualitatively similar to that described by Hope-Simpson [5]. There is a gradual increase in the number of cases of zoster in children as the proportion of the population with experience of the virus increases. After this there is some indication of a plateau of cases among young adults before the number of cases rises once again in older individuals. The peak in the number of cases of zoster is experienced by those in their fifties. There is then a decline in the number of cases, 
Table 3. Published sets of data used to estimate the relative pattern of the occurrence of zoster cases with age shown in Figure 2

$$
\begin{gathered}
\text { Location } \\
\text { (ref) }
\end{gathered}
$$

Gothenburg [54]

Rochester, Minnesota [35]

Cirencester, England [5]

Edinburgh, Scotland [33]

Dumfriesshire, Scotland [55]

New York [56]

New South Wales [44]

Hawick [57]

$$
\begin{array}{cc}
\text { Study } & \text { Sample } \\
\text { dates } & \text { size }
\end{array}
$$

No. age

classes

$\begin{array}{rr}1954-63 & 666^{*} \\ 1945-59 & 590 \\ 1947-62 & 192 \\ 1947-48 & 184 \\ 1969-82 & 151 \\ 1964-66 & 108 \\ 1982-84 & 89 \\ 1948-55 & 81\end{array}$

Mean age of disease

\section{$51 \cdot 4$}

$48 \cdot 5$

$52 \cdot 9$

$47 \cdot 8$

$49 \cdot 9$

$54 \cdot 4$

$52 \cdot 5$

$53 \cdot 8$

* Each set of data is comprised of an observed age profile for zoster incidence. Weighted analysis of variance on arcsine transformed prevalence within age groups indicates a significant effect of age on zoster prevalence $\left(\mathrm{F}_{8,70}=10.56, P<0.0001\right)$ but no significant difference between studies $\left(\mathrm{F}_{9.70}=0.065, P>0.05\right)$.

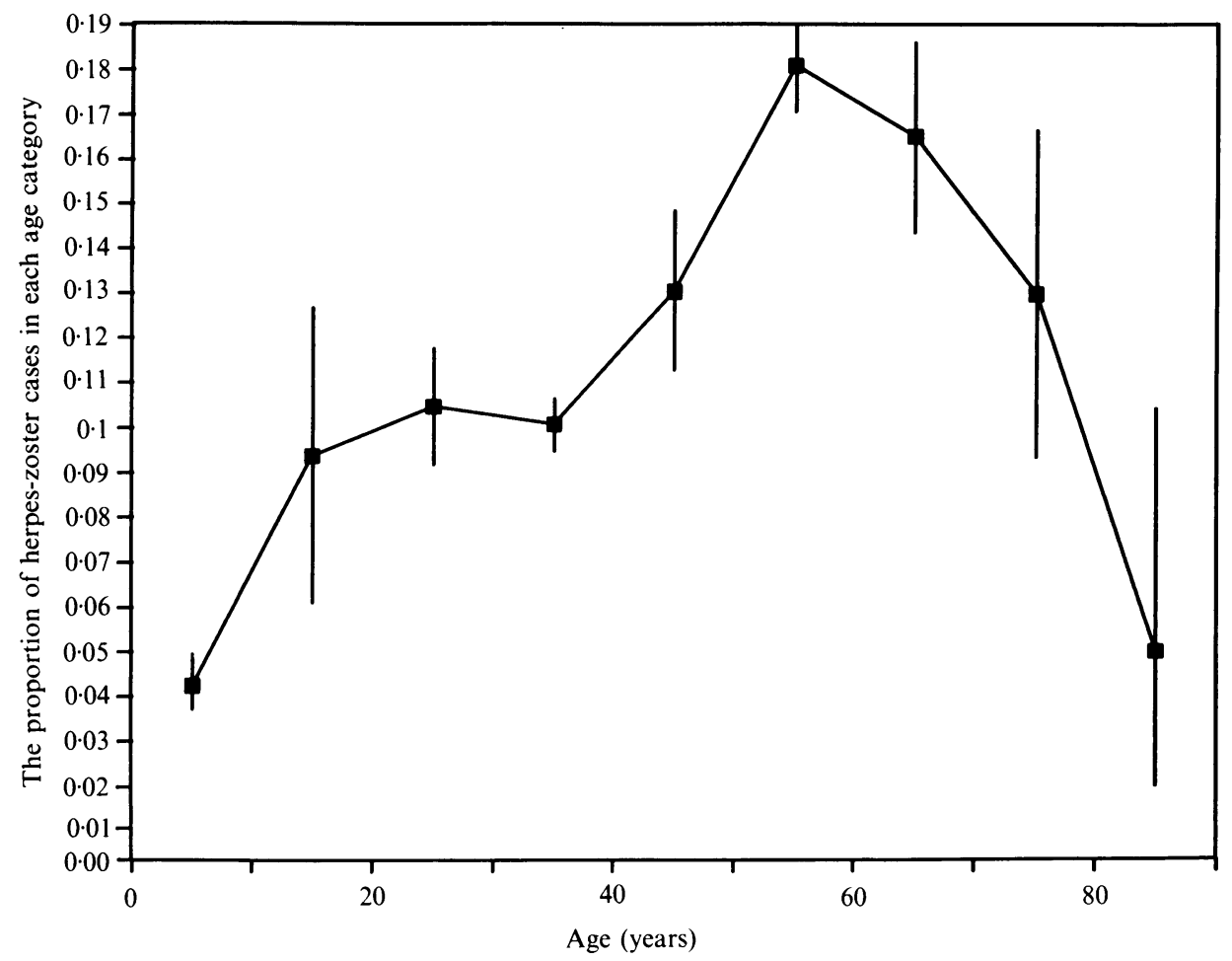

Fig. 2. The means of the proportion of all zoster cases in ten-year age classes derived from the data sets in Table 3. The means and standard errors (shown as bars) were weighted according to sample size.

presumably brought about by the reduction in the size of the population amongst the age groups where mortality is high. Although the standard errors are relatively large these data do serve as a basis for comparison with the results of the model.

Parameters which describe the probability of reactivation and the duration of zoster. There is no way of directly measuring the magnitude of any parameters which 
(a)

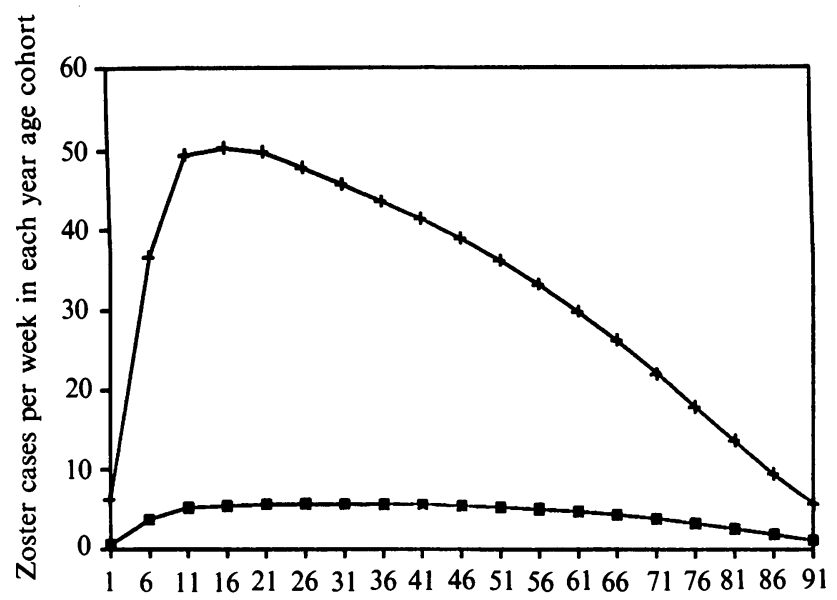

Age (years)

(b)

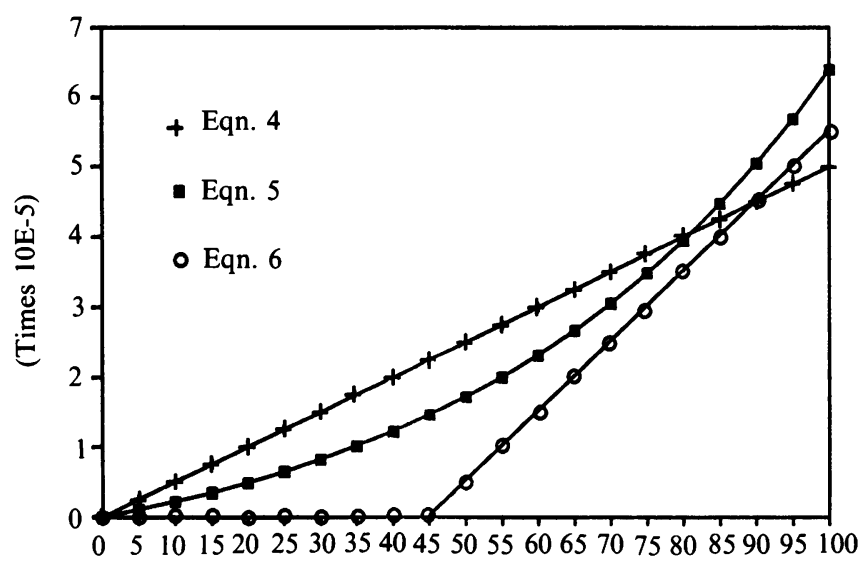

(c)

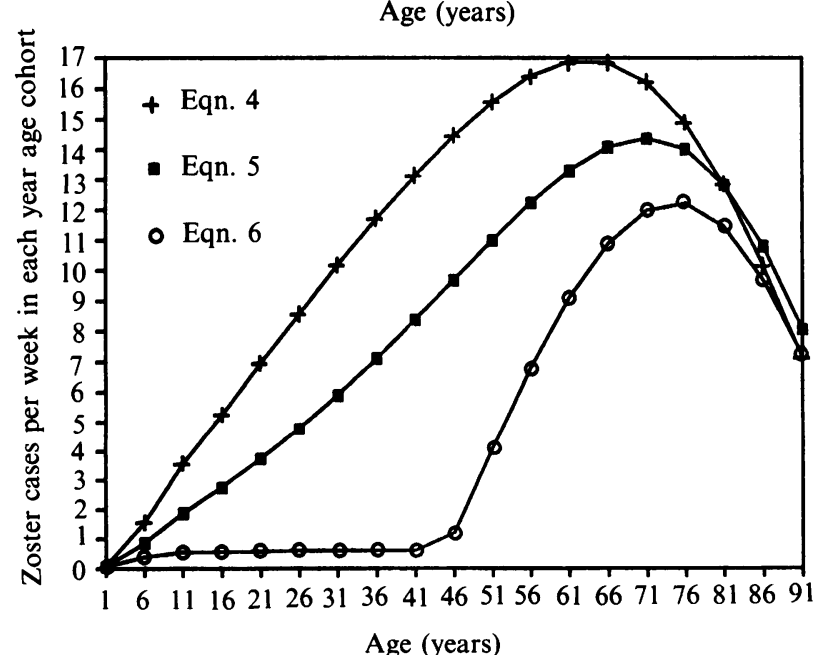

Age (years) 
control the reactivation of the virus, and estimates of the rate of zoster incidence vary greatly, from 1.1 to 4.8 per 1000 [35, 57]. The paucity of reliable data means that the model cannot be tested by comparing predicted and observed absolute prevalences of disease. Only the relative prevalence of disease between age classes, as displayed in Fig. 2, can be used to compare with predictions from the model. The sensitivity of the pattern to changes in the size of parameters controlling the rate of increase in the probability of reactivation in equations (4) and (5) was assessed. The absolute number of cases of zoster predicted by the model was sensitive to the value of the parameters in the reactivation function, but the qualitative patterns for the number of cases remained consistent (see Fig. 3a).

The rate of recovery from an episode of herpes-zoster $(\gamma)$ was determined from the mean duration of cases observed by Straus [14] and Troller [56]. The value used was 28 days.

Given the crudeness of these epidemiological data, the above parameter estimates (particularly the force of infection estimates) are necessarily crude. However, varying these parameters over their biologically reasonable ranges does not affect the following results in a qualitative way.

\section{RESULTS}

The equilibrium pattern of age of zoster cases derived from the model under the different hypotheses of how reactivation is controlled are shown in Fig. 3a. They should be compared with the observations on the age of zoster reactivation shown in Fig. 2.

\section{External precipitants}

The hypothesis that chance events control reactivation, represented by a constant reactivation function (eqn. 3), generates the results in Fig. 3a. The peak incidence of zoster in the model occurs at the age of 16 , when most people are carrying the virus. After this point the incidence of herpes-zoster tails off. This is because the number of virus carriers is depleted through both death and people moving into the zoster category, and because there is no further increase in the probability of reactivation. Changing the value of the constant probability used in the reactivation function $(\alpha)$ alters the magnitude, but not the shape, nor the position of the maximum, of the curve (Fig. 3a). In comparison with the peak in the observed prevalence (Fig. 2) the expected peak, generated by this model, clearly occurs at far too early an age. It appears from this analysis that precipitating factors which would occur at random, with a Poisson distribution as the simplest model, are not the main influence on the timing of zoster reactivation. Thus, there must be some other influence on the probability of reactivation.

Fig. 3. The equilibrium distribution of zoster cases with age derived from the varicella-zoster virus model described. Fig. 3a. The recrudescence function (Equation 3 ) represents a constant probability of recrudescence with age. The two lines represent values of $0.001(\square)$ and $0.01(X)$ for $\alpha$, demonstrating the potential influence of this parameter. Fig. $3 \mathrm{~b}$ and $3 \mathrm{c}$. The influence of age on zoster recrudescence in the varicella-zoster model. (b) The three functions of age used in the model simulations; Equations 4,5 and 6. (c) The corresponding age distributions of herpes-zoster cases generated with these recrudescence functions. 


\section{The influence of age on reactivation}

A constant decline in specific immunity in the host is represented in the model by a linear increase in the reactivation function $(\rho(a))$ with age (eqn. 4). In this case the level of herpes-zoster incidence continues to increase to a much later age (Fig. 3c). This increase continues until it is offset by death and the removal of virus carriers by reactivation. This model generates a later peak occurrence, and is therefore a better representation of the observed pattern. Other functions were also used to represent specific hypotheses for how the immune system may be influenced by age. Equation (5) portrays a gradually weakening immune system and equation (6) a discrete event which generates a compromised immune system. These hypotheses do alter the expected pattern of the age of cases of zoster (Fig. $3 \mathrm{~b}, \mathrm{c})$. However, because of the crudeness of the observed data it is unclear which hypothesis provides the best fit. The important point is that the probability of reactivation increases with age.

\section{DISCUSSION}

This paper presents a simple mathematical model as a conceptual framework for exploring the population biology of varicella-zoster virus. The particular aim of the study was to examine the mechanisms which generate the observed age distribution of viral reactivation, as manifested in the observed incidence of zoster. The main result to emerge from this analysis is that models in which the probability of viral reactivation increases with host age provide the best representation of the observed data. There is also an indication that the increase in reactivation with age may be faster than linear but this is less certain. These results bear out the tentative conclusions about the virus-host system reached by Hope-Simpson [5], which were based on observations from cases reported to only one general practice. However, it appears that transience in specific cell-mediated immunity rather than falling antibody levels allows the virus to reactivate [28-30].

\section{Model refinements}

This first version of our model for varicella and zoster epidemiology is necessarily crude. It makes a number of simplifying assumptions which we consider in the following sections, both in terms of their effects on the behaviour of the model and in terms of the need for future work.

Transmission of varicella. In an episode of varicella, virus is shed from the throat prior to, and during, the emergence of lesions in the skin, and from the lesions themselves [13]. This has two consequences for the model. (i) Infectiousness, which is present before skin lesions form [33,42], is likely to increase after their emergence. The relative importance of transmission from skin and throat lesions has never been quantified, although virus is very difficult to extract from the oesopharynx in comparison to skin lesions [1]. Thus, the assumption that transmission coefficients remain constant through the course of infection could be invalid. (ii) Infection with virus from skin lesions is likely to require closer contact between susceptible and infected individuals than is needed for infection with virus from throat lesions. In a community not all susceptibles are as likely to be 
infected by virus from a particular infectious individual because of social, spatial and behavioural heterogeneity. The difference in importance of the two transmission routes will highlight the importance of social groups, such as school classes, in the epidemiology of the virus.

In general these social groups are thought to be responsible for generating seasonal variation in the incidence of viral infections in developed countries $[37,58]$. This seasonal pattern of incidence frequently induces longer-term regular oscillations in disease incidence [59], although it is well documented that such behaviour is not apparent in the observed incidence of varicella [6, 7]. This lack of long-term periodicity may be a result of the complexities in varicella transmission mentioned here. The dynamics of varicella incidence do not effect the stable state results presented in this paper.

The first connection noticed between varicella and zoster was cases of varicella acquired from zoster patients [60]. Other reports of this sort of transmission of the virus are common $[4,61]$ and zoster was shown to have a statistically significant influence on levels of varicella in a boarding school [62]. However, in general it appears that zoster is a much less infectious disease than varicella [33] and its influence is in any case implicit in the calculation of the force of infection for varicella. Hence, for the purposes of this initial model, varicella caught from zoster is ignored. The influence of zoster transmitting VZV can be observed in the persistence of the virus in small communities; this will be explored in full elsewhere.

Zoster incidence. (i) Because the two variables, time since initial infection $(\tau)$ and age $(a)$, are strongly correlated, and because most initial infection occurs at a similar age, there is no way of clearly differentiating which of them is influencing the system. Thus, in our model we used a recrudescence function which was dependent on age in equation (4). If age is replaced by time since initial infection then the results in Figure 3 remain the same.

(ii) Repeated cases of zoster are few in number [5, 16, 32-35]. However, because of the detrimental effect of increasing age on general immune competence, VZVspecific immunity is not as readily reconstituted during an episode of zoster in the elderly [28]. Consequently, someone who has just suffered from a case of zoster may be more prone to viral reactivation than someone who has just had varicella.

(iii) As a supplementary hypothesis Hope-Simpson [5] suggested that contact with varicella cases may restore the protection conferred by a host's immunity against latent virus. If this is the case it has very important implications for vaccination [22].

Amongst the herpes viruses, records of varicella-zoster virus incidence are the most extensive. This is because there is a distinctive progression of disease, which makes the recording of cases straightforward. However, even for varicella and zoster, large reliable data sets are scarce. In addition to model refinements, to increase our knowledge of varicella and zoster, more data should be collected. In the case of varicella, the acquisition of further serological profiles would be beneficial. In particular, these should be from large samples, with wide age ranges, which are finely stratified according to age. Equivalent, zoster studies are limited to reported cases. These cases should be systematically notified if the relationship between the diseases is to be fully understood. 


\section{ACKNOWLEDGEMENTS}

We thank the SERC for financial support and D. J. Nokes, M. E. Halloren and R. M. Anderson for helpful discussions.

\section{APPENDIX}

In this appendix the full set of equations used for the mathematical model are presented. A brief explanation of the calculation of forces of infection for varicella is included.

The full mathematical model describing the status of a population with respect to infection by varicella-zoster virus is as follows:

$$
\begin{gathered}
\frac{\partial M(a, t)}{\partial a}+\frac{\partial M(a, t)}{\partial t}=-(\mu(a)+\delta) M(a, t) \\
\frac{\partial S(a, t)}{\partial a}+\frac{\partial S(a, t)}{\partial t}=\delta M(a, t)-(\lambda(a, t)+\mu(a)) S(a, t) \\
\frac{\partial E(a, t)}{\partial a}+\frac{\partial E(a, t)}{\partial t}=\lambda(a, t) S(a, t)-(\mu(a)+\sigma) E(a, t) \\
\frac{\partial I(a, t)}{\partial a}+\frac{\partial I(a, t)}{\partial t}=\sigma E(a, t)-(\mu(a)+v) I(a, t) \\
\frac{\partial V(a, t, \tau)}{\partial a}+\frac{\partial V(a, t, \tau)}{\partial t}+\frac{\partial V(a, t, \tau)}{\partial \tau}=-(\mu(a)+\rho(a, \tau)) V(a, t, \tau) \\
\frac{\partial Z(a, t)}{\partial a}+\frac{\partial Z(a, t)}{\partial t}=\int_{0}^{a} V(a, t, \tau) \rho(a, \tau) d \tau-(\mu(a)+\gamma) Z(a, t) .
\end{gathered}
$$

The state variables $M(a, t), S(a, t), E(a, t), I(a, t), R(a, t), V(a, t, \tau)$ and $Z(a, t)$ are the numbers of people in the population maternally immune, susceptible, infected but not yet infectious, infectious, with virus dormant and suffering from zoster, respectively. Implicit in the model is a group of those who have recovered from zoster. This group is immune to subsequent infection, as are those in the categories $V(a, t, \tau)$ and $Z(a, t)$, and simply remain in this implicit category until death. The total population is assumed to be constant, and is the sum of the state variables plus the implicit recovered category. The boundary conditions at age zero, i.e. at birth are:

$$
M(0, t)=\int_{0}^{\infty} N(a, t) \mu(a) d a ; \quad S(0, t)=E(0, t)=I(0, t)=V(0, t, \tau)=Z(0, t)=0 .
$$

At birth all children are assumed for simplicity to enter the maternal immunity category $M(a, t)$. From this group they enter the susceptible category $S(a, t)$ at a rate $\delta$, which is the inverse of the duration of maternal antibody persistence. People are also removed from the maternally immune category, as they are from all other categories, at an age-dependent death rate $\mu(a)$. Once in the susceptible category people became infected at an age-dependent rate $\lambda(a, t)$. When infected they move from the incubation state, $E(a, t)$, at a rate $\sigma$, to the infectious state 
$I(a, t)$, from which they recover at a rate $\nu$. People enter the 'virus carriers' category on initial infection with the virus, which means that the boundary condition for $\tau=0, V(a, t, 0)$ is $\lambda(a, t) . S(a, t)$, the number of people infected at time $t$. In effect people are in the 'virus carriers' group while they progress through the incubating and infectious groups. Across the range of times since initial infection $(\tau$ values) people in the group $V(a, t, \tau)$ suffer from zoster emergence at a rate $\rho(a, \tau)$, recovery from which occurs at the rate $\gamma$.

\section{The force of infection}

A function for transmission dependent upon age and time has been used extensively in studies of the epidemiology of directly transmitted microparasites $[20,58,45]$. This takes the form:

$$
\lambda(a, t)=\int_{0}^{\infty} \beta\left(a^{\prime}, a\right) I\left(a^{\prime}, t\right) d a^{\prime}
$$

where susceptibles of a specific age group $(a)$ are infected by those infectious from all the age groups $\left(a^{\prime}\right)$ in a manner dependent upon the ages of both the susceptibles $(a)$ and the infectious $\left(a^{\prime}\right) . \beta\left(a^{\prime}, a\right)$ is a function describing the probability of a susceptible of age $a$ being infected by an infectious person of age $a^{\prime}$. For the purpose of modelling, this force of infection is calculated for $n$ discrete age groups and $\beta\left(a^{\prime}, a\right)$ is described by a matrix $\beta_{i j}$ of transmission coefficients. This is the 'Who Acquires Infection From Whom' (WAIFW) matrix, which has been extensively described [19]. In the calculation of the $n$ values for this matrix we use a form of the matrix :

\begin{tabular}{ccccc}
\multicolumn{4}{c}{$i$} \\
\\
& 1 & 1 & 3 & 4 \\
$j$ & 1 & 2 & 3 & 4 \\
3 & 3 & 3 & 4 \\
4 & 4 & 4 & 4
\end{tabular}

which describes a peak in transmission amongst children of school age. This form of the matrix is epidemiologically sensible since it is believed that the majority of transmission of childhood microparasitic infections takes place within schools (36).

\section{The steady state}

In practice, this paper considers the steady state of equations (A1) to (A8), obtained by setting all time dependencies to zero. From this we obtain a set of ordinary differential equations describing the equilibrium age structure of primary infection and the re-emergent disease.

\section{REFERENCES}

1. Weller TH. Varicella-herpes zoster virus. In: Evans AS, ed. Viral infections of humans, epidemiology and control. New York: Plenum Medical Book Company, 1989: 659-83.

2. Christie AB. Infectious diseases. Volume 1. Edinburgh: Churchill Livingstone, 1987: 376-87.

3. London WP, Yorke JA. Recurrent outbreaks of measles, chickenpox and mumps. I. Seasonal variation in contact rates. Am J Epidemiol 1973; 98: 453-68. 
4. Olsen LF, Schaffer WM. Chaos versus noisy periodicity: alternative hypotheses for childhood epidemics. Science $1990 ; 249$ : 499-504.

5. Hope-Simpson RE. Infectiousness of communicable diseases in the household. Lancet 1952; ii : $549-54$.

6. Hope-Simpson RE. Studies on shingles - is the virus ordinary chickenpox virus? Lancet 1954 ; ii : 1299.

7. Hope-Simpson RE. The nature of herpes-zoster: a long-term study and a new hypothesis. Proc Roy Soc Med 1965; 58: 9-20.

8. Takahashi M. Chickenpox virus. Adv Virus Res $1983 ; 28: 285-348$.

9. Plotkin SA. Live varicella vaccine: the third act? Vaccine $1986 ; 4: 74$.

10. Just M, Berger R, Luescher D. Live varicella vaccine in healthy individuals. Postgrad Med J 1985 ; 61 (suppl 4) : 129-32.

11. Plotkin SA. Varicella vaccine: a point of descision. Pediatrics $1986 ; 78$ : 705-7.

12. McLean G. Compulsory vaccination. Aust Fam Phys 1988; 17: 12 .

13. Plotkin SA. Clinical and pathogenic aspects of varicella-zoster. Postgrad Med J 1985; 61 (suppl 4): $7-14$.

14. Straus SE, Ostrove JM, Inchauspe G, et al. Varicella-zoster virus infections. Biology, natural history, treatment and prevention. Ann of Int Med 1988; 108: 21-37.

15. Weller TH. Varicella and herpes-zoster: changing concepts of the natural history, control and importance of a not-so-benign virus. N Engl J Med 1983; 309: 1362-440.

16. Head H, Campbell AW. The pathology of herpes-zoster and its bearing on sensory localisation. Brain $1900 ; 23: 353$.

17. Hyman RW, Ecker JR, Tenser RB. Varicella-zoster virus RNA in human trigeminal ganglia. Lancet 1983 ; ii : 814-16.

18. Gilden DH, Vafai A, Shtram Y, Becker Y, Berli M, Wellish M. Varicella-zoster virus DNA in human sensory ganglia. Nature $1983 ; 306: 478-80$.

19. Anderson RM, May RM. Age-related changes in the rate of disease transmission: implications for the design of vaccination programmes. J Hyg 1985; 94 : 365-436.

20. Anderson RM, May RM. Vaccination and herd immunity to infectious disease. Nature $1985 ; 319: 323-9$.

21. Takahashi M, Kamiya H, Baba K, Asano Y, Ozaki T, Horiuchi K. Clinical experience with Oka live varicella vaccine in Japan. Postgrad Med J 1985; 61 (suppl. 4) : 61-7.

22. Garnett GP, Grenfell BT. The epidemiology of varicella-zoster virus: the influence of varicella on the prevalence of herpes-zoster. Epidemiol Infect 1992; 108: 513-528.

23. Stokes J Jr. Varicella-herpes zoster group. In: Rivers TM, Horsfall FL Jr. eds. Viral and rickettsial infections of man. Philadelphia: J. B. Lippincott, 1959: 773-9.

24. Juel-Jenson BE. The natural history of shingles. J Roy Col Gen Pract 1970; 20 : 323-7.

25. Juel-Jensen BE. Herpes-simplex and zoster. Br Med J 1973: 406-10.

26. Myers MG. Varicella and herpes-zoster: comparison in the old and young. Geriatrics 1977; 32: $77-9$.

27. Mazur MH, Dolin R. Herpes-zoster at the NIH : a 20-year experience. Am J Med 1978; 65 : $738-44$.

28. Millar AE. Selective decline in cellular immune response to varicella-zoster in the elderly. Neurology $1980 ; 30$ : $582-7$.

29. Berger R, Florent G, Just, M. Decrease of the lymphoproliferative response to varicella-zoster virus antigen in the aged. Infect Immun $1981 ; 32: 24-7$.

30. Burke BL, Steele RW, Beard OW, Wood JS, Cain TD, Mamer DJ. Immune responses to varicella-zoster in the aged. Arch Intern Med 1982;142: 291-3.

31. Rook G. Immunity to viruses, bacteria and fungi. In: Roitt IM, Brostoff J, Male DK, eds. Immunology. Edinburgh: Churchill Livingstone, 1989; 16.1-16.

32. Seiler HE. A study of herpes-zoster particularly in relationship to chickenpox. J Hyg 1949 ; 17: $253-62$.

33. Gordon JE. Chickenpox : an epidemiological review. Am J Med Sci 1962; 244 : 362-85.

34. Burgoon CF, Burgoon JS, Baldridge GD. The natural history of herpes-zoster. JAMA 1957; 164: $265^{-9}$.

35. Ragozzino MW, Melton LJ, Kurland LT, Chu CP, Perry HO. Population based study of herpes-zoster and its sequelae. Medicine 1982; 61:310-16. 
36. Fox JP, Elveback L, Scott W, Gatewood L, Ackerman E. Herd immunity: basic concept and relevance to public health immunisation practices. Am J Epidemiol 1971; 94: 179-89.

37. Anderson RM, May RM. Vaccination against rubella and measles: quantitative investigations of different policies. J Hyg 1983; 90 : 259-25.

38. Anderson RM, May RM. Population biology of infectious diseases. Part 1. Nature 1979; 280: $361-7$.

39. Gershon AA, Raker R, Steinberg S, Topf-Olstein B, Drusin LM. Antibody to varicella-zoster virus in parturient women and their offspring during the first year of life. Pediatrics $1976 ; 58$ : $692-6$.

40. Ozaki T, Nagai H, Kimura T, Ichikawa T, Suzuki S. The age distribution of neutralising antibodies against varicella-zoster virus in healthy individuals. Biken $J$ 1980; 23: 9-14.

41. Trlifayova J, Porkorny J, Svandova E, Ryba M. Study of persistence of maternal antibodies to varicella-zoster virus by indirect haemagglutination, with result control by radioimmunoassay. J Hyg Epidemiol Microbiol Immunobiol 1982; 28 : 65-73.

42. Gordon JE, Meader FM. The period of infectivity and serum prevention of chickenpox. JAMA $1929 ; 93$ : 2013-15.

43. Ross HA, Lencher E, Reitman G. Modification of chickenpox in family contacts by administration of gamma globulin. New Engl J Med 1962; $267: 369-76$.

44. Troller J. Herpes-zoster in general practice. Aust Fam Phys 1987; 16: 1133-40.

45. Grenfell BT, Anderson RM. The estimation of age-related rates of infection from case notifications and serological data. J Hyg 1985; 95 : 419-36.

46. Schneweis KE, Krentler Ch, Wolff MH. Durchseuschung mit dem Varicella-zoster Virus und serologische Feststellung der erstinfections Immunität. Dtsch Med Wschr 1985; 110: 453-7.

47. Muench R, Nassim C, Nika S, Sullivan-Boylai JZ. Seroepidemiology of varicella. J Infect Dis $1986 ; 153: 153-5$.

48. Leventon-Kriss S, Yoffe R, Rannon L, Modan M. Seroepidemiological aspects of varicellazoster virus infections in an Israeli Jewish population. Israeli J Med Sci 1978; 14: 766-70.

49. Eguilez GC, Trallero EP, Arenzana JMG. Seroepidemiology of varicella in children from Spain. J Infect Dis $1987 ; 156 ; 851$.

50. Gershon AA, Steinberg SP. Antibody responses to varicella-zoster virus and the role of antibody in host defence. Am J Med Sci 1981; 282: 12-17.

51. Collins SD, Wheeler RE, Shannon RD. The occurrence of whooping cough, chickenpox, mumps and German measles in 200,000 surveyed families in 28 large cities. United States - 1943. Washington: N.I.H. Division of Public Health Methods. Special study series No. 1.

52. Sullivan-Boylai JZ, Yin EK, Cox P, et al. Impact of chickenpox on households of healthy children. Pediatr Infect Dis $1987 ; 6: 33-5$.

53. Saito M, Haruyama C, Ohba H, Wada A, Takeuchi Y. A seroepidemiological study on varicella. Kanseshogaka Zasshi $1987 ; 61: 783-8$.

54. Hellgren L, Hersle K. A statistical and clinical study of herpes-zoster. Geront Clin $1966 ; 8$ 70-6.

55. Wilson JB. Thirty-one years of herpes-zoster in a rural practice. Br Med J 1986; 293 1349-51.

56. Millar LH, Brunell PA. Zoster, reinfection or activation of latent virus? Am J Med 1970; 49: $480-3$.

57. McGregor RM. Herpes-zoster, chickenpox and cancer in general practice. Br Med J 1957; i: $84-7$.

58. Schenzle D. An age-structured model of pre- and post-vaccination measles transmission. IMAJ Math Appl Med Biol 1984; $1: 169-91$.

59. Anderson RM, Grenfell BT, May RM. Oscillatory fluctuations in the incidence of infectious disease and the impact of vaccination: time series analysis. J Hyg 1984; 93 : 587-608.

60. Jako GJ, Jako RA. Short historical note: connection between varicella and herpes-zoster. J Med 1986; $17: 267-70$.

61. Pallett AP, Nicholls MWN. Varicella-zoster: reactivation and reinfection ? Lancet 1986 ; i : 160.

62. Schools Epidemics Committee. The relationship between chickenpox and herpes-zoster. Medical Research Council, Special Reports Series, Epidemics in Schools 1938; No 227 : 181-4. 